\title{
A Música na educação infantil como uma ferramenta no desenvolvimento cognitivo da criança
}

Music in early childhood education as a tool in child's cognitive development

La música en la educación de la primera infancia como herramienta en el desarrollo cognitivo del niño

Recebido: 05/05/2020 | Revisado: 05/05/2020 | Aceito: 13/05/2020 | Publicado:21/05/2020

Geysa Luiza de Souza Santos

ORCID: https://orcid.org/0000-0003-2244-8917 Instituto Federal de Educação, Ciência e Tecnologia de Mato Grosso, Brasil

E-mail: geysa.santos@svc.ifmt.edu.br

Edione Teixeira de Carvalho

ORCID: https://orcid.org/0000-0002-1208-3961

Instituto Federal de Educação, Ciência e Tecnologia de Mato Grosso, Brasil

E-mail: edione.carvalho@svc.ifmt.edu.br

Odete Selva

ORCID: https://orcid.org/0000-0002-4469-1267

Secretaria Municipal de Educação de Campo Verde, Brasil

E-mail:odete_selva@hotmail.co

\section{Resumo}

A música é uma forma de linguagem que pode desenvolver capacidades que serão de fundamental importância para o desenvolvimento da criança. No cotidiano escolar, a música enquanto área de conhecimento, com características de linguagem específica, pode ampliar o conhecimento através das atividades musicais desenvolvidas em sala de aula, pois é em seu interior que acontecem as mediações e as trocas de experiências que tanto auxiliam no desenvolvimento cognitivo da criança. Desse modo, faz-se necessário desmistificar a ideia de que a música na escola esteja a serviço das apresentações/comemorações do calendário escolar. Sendo assim, a presente pesquisa objetivou analisar a importância da música na educação infantil pelo olhar da professora que atua neste segmento. As colaboradoras da pesquisa foram professoras de uma escola pública do município de Campo Verde - MT. Para 
tanto, a pesquisa foi realizada sob uma abordagem qualitativa e os procedimentos adotados foram a pesquisa de campo, bem como a pesquisa bibliográfica. A análise de conteúdo foi a técnica utilizada para realizar a análise dos dados. Concluiu-se que a música na educação infantil é uma ferramenta importante e necessária para o desenvolvimento dos aspectos cognitivos, linguísticos, psicomotores e sócio-afetivos, além de possibilitar a aquisição de novos conhecimentos num ambiente prazeroso e divertido, onde a criança se sente estimulada e provocada para se envolver e desenvolver.

Palavras-chave: Educação musical; Cognição; Professoras; Infância.

\begin{abstract}
Music is a form of language that can develop skills that will be of fundamental importance for the child's development. In the school routine, music as an area of knowledge, with specific language characteristics, can expand knowledge through musical activities developed in the classroom, as it is within it that mediations and exchanges of experiences take place that help so much in the development child's cognitive function. Thus, it is necessary to demystify the idea that music at school is at the service of school calendar presentations / celebrations. Therefore, this research aimed to analyze the importance of music in early childhood education through the eyes of the teacher who works in this segment. The research collaborators were teachers at a public school in the municipality of Campo Verde - MT that attends early childhood education. Therefore, the research was carried out under a qualitative approach and the procedures adopted were field research, as well as bibliographic research. Content analysis was the technique used to perform the data analysis. Thus, it was concluded that music in early childhood education is an important and necessary tool for the development of cognitive, linguistic, psychomotor and socio-affective aspects, in addition to enabling the acquisition of new knowledge in a pleasant and fun environment, where the child feels stimulated and provoked to get involved and develop.
\end{abstract}

Keywords: Musical education; Cognition; Teachers; Childhood.

\title{
Resumen
}

La música es una forma de lenguaje que puede desarrollar habilidades que serán de importancia fundamental para el desarrollo del niño. En la rutina escolar, la música como un área de conocimiento, con características específicas del lenguaje, puede expandir el conocimiento a través de actividades musicales desarrolladas en el aula, ya que es dentro de él que tienen lugar mediaciones e intercambios de experiencias que ayudan mucho en el 
desarrollo. función cognitiva del niño. Por lo tanto, es necesario desmitificar la idea de que la música en la escuela está al servicio de las presentaciones / celebraciones del calendario escolar. Por lo tanto, esta investigación tuvo como objetivo analizar la importancia de la música en la educación de la primera infancia a través de los ojos del maestro que trabaja en este segmento. Las colaboradoras de la investigación fueron docentes de una escuela pública en el municipio de Campo Verde - MT que asiste a la educación infantil. Por lo tanto, la investigación se realizó bajo un enfoque cualitativo y los procedimientos adoptados fueron la investigación de campo, así como la investigación bibliográfica. El análisis de contenido fue la técnica utilizada para realizar el análisis de datos. Así, se concluyó que la música en la educación de la primera infancia es una herramienta importante y necesaria para el desarrollo de aspectos cognitivos, lingüísticos, psicomotores y socioafectivos, además de permitir la adquisición de nuevos conocimientos en un ambiente agradable y divertido, donde el niño se siente estimulado y provocado para involucrarse y desarrollarse.

Palabras clave: Educación musical; Cognición; Maestras; Infancia.

\section{Introdução}

A música é uma linguagem de grande relevância no contexto escolar, pois é uma ferramenta que auxilia na riqueza dos estímulos proporcionando o desenvolvimento de aspectos positivos na vida da criança. Para Loureiro (2001), a escola exerce um papel fundamental no estudo da cultura musical, pois é dentro dela que se realizam as trocas de experiências pessoais, intuitivas e diferenciadas, cabendo então, à escola fazer a mediação desses saberes. A criança que vivencia a música desde a mais tenra idade tem ganho em diversas áreas de sua formação, o que caracteriza que a música pode ser considerada como um instrumento que facilita no processo educacional.

De acordo o Parecer CNE/CEB No 12/2013:

O estudo de música é instrumento para modificar o funcionamento do cérebro em dimensões ligadas às aprendizagens dos conhecimentos formais e de outros fazeres do ser humano. Ela mobiliza inúmeras áreas do cérebro, integrando-as de forma única em relação a outras atividades humanas (Brasil, 2013).

Para Brito (2003, p. 35), “o envolvimento das crianças com o universo sonoro começa ainda antes do nascimento, na fase intrauterina, onde os bebês já convivem com um ambiente de sons provocados pelo corpo da mãe”. A investigação sobre a presença da música na 
educação infantil com sua linguagem específica foi instigada com intuito de desmistificar a ideia de que a música está a serviço apenas das apresentações e comemorações estabelecidas pelo calendário escolar. Nesse sentido Brito (2003), ressalta:

\begin{abstract}
Ainda percebe-se fortes resquícios de uma concepção de ensino que utilizou a música, como suporte para a aquisição de conhecimentos gerais, condicionamento da rotina, comemoração de datas diversas, etc. Os cantos (ou musiquinhas) eram quase sempre acompanhados de gestos e movimentos, que pela repetição tornavam-se mecânicos e estereotipados, automatizando o que antes era - ou poderia vir a ser - expressivo. A música, nesses contextos, era apenas um meio para atingir objetivos considerados adequados à instrução e à formação infantil (Brito, 2003, p. 51).
\end{abstract}

Numa outra perspectiva, a prática da linguagem musical na escola deve oportunizar o contato da criança com o universo da música e com os inúmeros benefícios que ela proporciona ao desenvolvimento infantil. Conforme Brito (2003), os momentos de troca e comunicação sonoros-musicais auxiliam o desenvolvimento afetivo e cognitivo, e as canções de roda, as parlendas, as cantigas de ninar e os jogos musicais contribuem para que essa relação se fortaleça.

Desse modo, a música é uma ferramenta que torna a realização do trabalho educativo, dentro da escola, mais prazeroso e significativo, envolvendo e desenvolvendo o aluno, considerando sempre sua vivência para que aconteça a integração entre o conteúdo musical e os saberes desenvolvidos no interior da escola (Santos, 2019). Para Drummond (2011), o conhecimento articulado com a experiência estética é recebido pela criança com intensidade singular, uma vez que agrega a felicidade de descobrir coisas novas, que a música, em particular, proporciona por despertar a emoção e induzi-la a gestos e movimentos, tão necessários ao seu amplo desenvolvimento.

A importância da música na educação infantil é o que esta investigação procura demonstrar para a formação humana, tendo em vista as possibilidades que ela pode proporcionar enquanto área de conhecimento. Dessa forma, o objetivo desta investigação é analisar a importância da música no desenvolvimento da criança sob o olhar da professora da educação infantil e quais benefícios ela traz no contexto educacional da criança. Por isso, a investigação foi centralizada na educação infantil, pois é nessa fase que se inicia um pleno desenvolvimento da criança, em todos os aspectos.

Assim, partindo do pressuposto de que a música desenvolve o equilíbrio e a sensibilidade do ser humano, é relevante que se destaque a sua importância em ser trabalhada desde a infância, considerando que a linguagem musical é uma ferramenta que pode auxiliar 
no processo de ensino-aprendizagem, além de contribuir para um ambiente mais alegre e receptivo (Santos, 2019).

Portanto, o estudo foi realizado com professoras da educação infantil, com enfoque na utilização da música em sala de aula. Foram aplicados questionários e a partir da análise realizada sobre os dados coletados, ficou evidenciado: que as professoras consideram a música uma ferramenta importante dentro e fora da sala de aula. Para elas, a música faz parte da vivência da criança e como tal deve ser trabalhada na escola, pois além de ser um recurso lúdico que encanta as crianças, também favorece na aquisição de novos saberes por meio das letras que trazem em seus contextos variados. A criança aprende brincando, num ambiente escolar agradável que acaba estimulando-a a participar cada vez mais das aulas.

\section{A Música na Educação Infantil}

A música como manifestação artística acompanha a humanidade ao longo de sua história, desenvolvendo qualidades essenciais no ser humano. Não se pode deixar de destacar os efeitos que ela proporciona em seu desenvolvimento, exercendo as mais distintas funções. É uma linguagem que pode desenvolver na criança, capacidades e habilidades que contribuem para um desenvolvimento integral (Santos, 2019).

Dessa forma, a convivência das crianças no espaço escolar, desenvolvendo atividades musicais tais, como tocar, ouvir, apreciar e imitar, favorecem o desenvolvimento cognitivo e emocional das mesmas, interferindo diretamente no desenvolvimento infantil em toda sua plenitude (Santos, 2019).

Com base em Vygotsky (1962, apud Fonseca, 2018, p. 69) "o desenvolvimento do sujeito humano se dá a partir das constantes interações com o meio social em que vive" e a música é uma ferramenta que se desenvolve no coletivo, nas relações desenvolvidas dentro da escola. Para Kebach (2016), na interação coletiva há trocas entre os indivíduos dos saberes experienciais construídos em seu entorno cultural, gerando assim, diferentes formas de enxergar o mundo. Essas experiências são construídas no decorrer da vida, tendo em vista que a música faz parte da vida de todo ser humano, desde o seu nascimento.

A relação do homem com o mundo não é uma relação direta, ela é mediada por meio de instrumentos que auxiliam a atividade humana. Na perspectiva sócio-histórica essa mediação é fundamental, pois é através dos instrumentos e signos que os processos de funcionamento psicológico são fornecidos pela cultura, conferindo à linguagem um papel de destaque no processo de pensamentos (Rego, 2014). 
Desse modo, à medida que a criança vai construindo e dominando a linguagem musical, principalmente no sentido de se relacionar com o seu meio, ela vai também desenvolvendo novas habilidades do seu modo de agir e pensar. Numa outra perspectiva, como bem coloca Gardner (1995), a música como uma linguagem própria do ser humano, deve ser trabalhada na escola, pois é apontada como uma das sete inteligências e, segundo ele, cada pessoa possui uma configuração própria de inteligências, que resulta na combinação das sete dimensões, que devem ser trabalhadas em conjunto na realização de uma atividade. Uma inteligência não pode ser menos valorizada em detrimento de outra, todas essas dimensões deveriam ser trabalhadas pela escola em harmonia, de forma que todas sejam contempladas no desenvolvimento da criança. A Teoria das Inteligências Múltiplas proposta por Gardner (1995) contemplam as seguintes inteligências: lógico-matemática, linguística, corporalcinestésica, espacial, musical, interpessoal e intrapessoal.

Ao considerar as diferentes habilidades, a escola estará dando oportunidade para que o aluno se destaque em pelo menos uma delas, ao contrário do que acontece quando se privilegiam apenas a capacidade: lógico-matemática e, linguística (Gardner, 1995). Em muitas escolas, onde não se trabalha a música como uma linguagem específica, ela é vista como uma ferramenta que está a serviço das comemorações e apresentações, distanciando, assim, da sua real finalidade enquanto linguagem que auxilia no desenvolvimento integral da criança. É preciso reconhecer que a música está além do prazer de entretenimento, ao qual é comumente associada, e de ser "supérflua" como muitos supõem.

Para tanto, a escola é o espaço que deveria proporcionar ao estudante todas as possibilidades para o seu desenvolvimento pleno e a música é uma linguagem importante a ser destacada na educação infantil, pois ela desenvolve múltiplas habilidades (Santos, 2019). Trabalhar com música na educação infantil, permite que a criança interaja com o ambiente musical, tendo em vista que ao cantar, ouvir e dançar ela expressa situações presentes na vivência de toda criança. Conforme Brito coloca (2003, p. 53),

[...] é preciso lembrar que a música é uma linguagem cujo conhecimento se constrói com base em vivências e reflexões orientadas. [...], pois as competências musicais desenvolvem-se com a prática regular e orientada, em contextos de respeito, valorização e estímulo a cada aluno, por meio de propostas que consideram todo o processo de trabalho, e não apenas o produto final (Brito, 2003, p. 53)

Por meio da música pode-se trabalhar a matemática, a linguagem, a coordenação motora, dentre outras dimensões, considerando sempre a ludicidade e o ambiente prazeroso 
que desperta na criança a atenção e a criatividade, desenvolvendo também a integração e a inclusão no grupo a que pertence. Essas relações desenvolvidas na escola são importantes, uma vez que trabalha e, reafirma a segurança, a confiança, autoestima, o sentimento de pertencimento ao grupo, que são fatores que interferem diretamente no processo de ensinoaprendizagem.

Sendo assim, a linguagem musical é essencial para o ser humano, não no sentido de formar profissionais ou artistas, mas sim como uma ferramenta que possibilita ao homem um maior desenvolvimento cognitivo e emocional, sobretudo na educação infantil que é a fase do desenvolvimento em que mais se desenvolve a linguagem musical. Nesse sentido, Rosa (1990) afirma:

A linguagem musical deve estar presente nas atividades [...] de expressão física, através de exercícios ginásticos, rítmicos, jogos, brinquedos e roda cantadas, em que se desenvolve na criança a linguagem corporal, numa organização temporal, espacial e energética. A criança comunica-se principalmente através do corpo, e cantando, ela é ela mesma, ela é seu próprio instrumento (Rosa, 1990, p. 22-23)

Nessa perspectiva, a música quando bem trabalhada na escola, contribui para que a criança desenvolva-se em sua plenitude como ser humano, fortalecendo e unindo a relação entre corpo, mente e alma, ressaltando assim, a sua importância na educação infantil como ferramenta educacional (Gatti, 2012). O filósofo grego Platão que viveu entre os séculos V e IV antes de Cristo, em sua obra A República dizia que era necessário modelar a alma e o caráter por meio da música, pois assim ela traria benefícios à formação moral do cidadão, assim como a ginástica, para o corpo. Estes dois grandes fenômenos trariam o equilíbrio entre corpo e alma (Santos, 2019).

A linguagem musical aqui discutida não é somente aquela utilizada nas comemorações e apresentações, mas aquela em que é despertado na criança ações que, integram o perceber, o pensar, o apreciar, o aprender, o recordar, o imaginar, o sentir, o criar, o expressar e o comunicar, ou seja, a música trabalhada como uma linguagem e as suas especificidades. Segundo Brito (2003), o modo como essas crianças percebem, apreendem e se relacionam com os sons, revela o modo como percebem, apreendem e se relacionam com o mundo que vêm explorando e descobrindo a cada dia.

Como bem coloca Rubem Alves (2018), 
A educação da nossa sensibilidade musical deveria ser um dos objetivos da educação. Os conhecimentos da ciência são importantes. Eles nos dão poder. Mas eles não mudam o jeito de ser das pessoas. A música, ao contrário, não dá poder algum. Mas ela é capaz de penetrar na alma e de comover o mundo interior da sensibilidade onde mora a bondade (Alves, 2018, p. 46).

Portanto, partindo do pressuposto de que a música desenvolve o equilíbrio e a sensibilidade do ser humano, é relevante compreender e reconhecer a sua importância na educação infantil, fase em que as crianças estão em pleno desenvolvimento em todas as áreas do conhecimento.

\section{Metodologia}

Essa investigação adotou como procedimento metodológico a pesquisa de campo, onde o objeto/fonte é abordado em seu ambiente próprio e, onde a coleta dos dados é feita nas condições naturais em que os fenômenos ocorrem, sem intervenção e manuseio por parte do pesquisador (Severino, 2007). Esse procedimento metodológico procura o aprofundamento das questões propostas, apresentando uma maior flexibilidade. Uma distinção da pesquisa de campo é que ela estuda um único grupo ou comunidade em termos de sua estrutura social, ou seja, ressaltando a interação de seus componentes. Além da pesquisa de campo foi utilizada também como procedimento metodológico, a pesquisa bibliográfica, que se constitui num procedimento formal para a aquisição de conhecimento sobre a realidade, conforme defende Severino:

A pesquisa bibliográfica é aquela que se realiza a partir do registro disponível, decorrente de pesquisas anteriores, em documentos impressos, como livros, artigos, teses e etc. Utiliza-se de dados ou de categorias teóricas já trabalhados por outros pesquisadores e devidamente registrados. Os textos tornam-se fontes dos temas a serem pesquisados. O pesquisador trabalha a partir das contribuições dos autores dos estudos analíticos constantes nos textos (Ibid, 2007, p. 122).

A natureza da pesquisa é aplicada no sentido de contribuição para a ampliação do conhecimento (Medeiros, 2019) e a abordagem é qualitativa como preconiza Pereira et al. (2018) e, na perspectiva em que trabalha com o universo das relações, das representações e da intencionalidade e que dificilmente pode ser traduzido em números e indicadores quantitativos.

O nível da pesquisa é a explicativa uma vez que: "tem como preocupação central 
identificar os fatores que determinam ou que contribuem para a ocorrência dos fenômenos, [...] explicando a razão e o porquê das coisas, aprofundando assim o conhecimento da realidade" (Gil, 2008, p. 28).

Os sujeitos da pesquisa foram 12 professoras da educação infantil do Centro Educacional Amerecilda Conceição Fernandes Rezende, localizado na Avenida São Lourenço, no 240, Bairro São Lourenço, Campo Verde - MT. As professoras selecionadas para esta investigação foram as que atuam na educação infantil, nas fases do Berçário II (1 ano), Maternal I ( 2 anos), Maternal II (3 anos) e Pré I (4 anos). Todas têm formação em Pedagogia, todavia não possuem formação na área musical. A técnica de pesquisa utilizada para realizar a coleta de dados foi por meio de questionário semi-estruturado o qual continha 04 questões.

A técnica adotada para a análise de dados foi: análise de conteúdo, fundamentada em Bardin (2016). O procedimento metodológico da análise de conteúdo foi a codificação que decompõe em partes o material coletado, categorizando-as, e do qual foi realizada a interpretação dos resultados obtidos.

\section{Resultados e Discussões}

Foi realizada a coleta de dados por meio da aplicação de questionário a 12 professoras do Centro Educacional Amerecilda Conceição Fernandes Rezende, localizado no município de Campo Verde - MT. Todas as professoras que responderam ao questionário atuam na educação infantil e tem formação em Pedagogia. Nenhuma possui formação musical. Os questionamentos foram:

1. Na sua visão, é importante trabalhar a música na educação infantil? Porque?

2. Você usa a música para desenvolver atividades com as crianças? Se sim, de que maneira?

3. Na sua opinião que contribuições a música traz para o desenvolvimento e aprendizagem da criança da educação infantil?

4. Na sua opinião, você acha que a música contribui para o desenvolvimento cognitivo da criança?

De acordo com as respostas das questões pôde-se inferir que a escola explora bastante a linguagem musical, não como linguagem específica, todavia dentro das possibilidades de 
cada professor no que se refere à linguagem musical. Algumas professoras utilizam a música em muitas ocasiões dentro da sala de aula, o que é bastante positivo. Foi verificado nas respostas apresentadas, que as professoras falavam com entusiasmo sobre utilizar essa ferramenta em suas aulas.

Na questão 1 foi abordado a importância de se trabalhar música. A maior parte das respostas apresentadas pelas professoras foi de ter um ambiente onde se trabalha de forma lúdica e prazerosa, e o desenvolvimento da oralidade de forma mais efetiva, da afirmação da autoestima, bem como, das suas ideias e valores, observaram também a questão da letra das canções, onde as crianças aprendem brincando e cantando. Destacaram ainda, a interação e a disposição das crianças em participar das aulas quando há música. Outro aspecto evidenciado foi o conhecimento se tornar mais amplo a partir do contato com a música, fazendo com que o aluno conheça o mundo a sua volta de maneira mais agradável, auxiliando assim, o processo de ensino-aprendizagem. Nesse sentido, Gatti (2012) coloca que:

A escola e o educador, juntos, devem trazer para dentro da instituição e das salas de aula diversos gêneros musicais, diversos estilos, proporcionando às crianças momentos de reflexão onde eles possam analisar as músicas apresentadas, fazendo com que eles possam expor suas opiniões e se tornem cada vez mais críticos. Assim, por serem crianças, elas não precisam ficar presas apenas às músicas infantis, que muitas vezes são padronizadas e não permitem que o conhecimento das crianças seja feito de uma forma mais rica (Gatti, 2012, 19).

Segundo Brito (2003), nessa fase é ideal que se explorem atividades musicais que contemplem a voz, a interpretação e criação de canções, jogos que reúnem som, movimento e dança, sonorização de histórias, apreciação musical, dentre outras. Brito (2003, p. 161) diz ainda que quando as crianças estão "ouvindo e, depois criando histórias, elas estimulam sua capacidade inventiva, desenvolvem o contato e a vivência com a linguagem oral e ampliam recursos que incluem o vocabulário, as entonações expressivas, as articulações, enfim, a musicalidade própria da fala".

No que se refere à utilização de música em sala de aula, as professoras responderam que na educação infantil ela é muito usada, em sua maioria, para os comandos da sala de aula, como a hora de sentar, a hora de guardar os brinquedos, hora de lavar as mãos, hora do lanche, dentre outros comandos. Observou-se também que muitas usam a música para fazer a acolhida e os acordos da sala de aula.

Num outro ponto, foi questionado acerca da contribuição da música para o desenvolvimento da aprendizagem na educação infantil. Neste ponto as professoras foram 
bem categóricas ao afirmarem que a música é um instrumento facilitador da aprendizagem, potencializando a oralidade, a construção da identidade, estimulando a motricidade, além de promover a interação entre as crianças, pelo fato de ser uma linguagem que está presente no conhecimento de mundo das mesmas. Favorece também o desenvolvimento de seu potencial criativo e sensível de ser, bem como a atenção, a concentração, a socialização, respeito a si próprio e com os outros, o raciocínio, o equilíbrio emocional, que são fatores que contribuem para a formação das crianças.

De acordo com Gatti (2012), na educação infantil é o momento da criança construir sua identidade, promover ainda mais seu desenvolvimento cognitivo, motor e também o afetivo, fazendo com que a mesma passe a interagir e a se socializar com outras crianças, percebendo a diversidade entre elas. Sendo assim, a educação infantil vivencia e passa por vários processos do desenvolvimento da criança, dentre eles, a aprendizagem e o processo de escolarização (Ibid, 2012). O estímulo que a música provoca nas crianças, contribui para que o conhecimento seja construído de uma forma mais divertida. Elas passam a ter mais criatividade, mais facilidade ao se expressar e o interesse pela aprendizagem aumenta cada vez mais (Gatti, 2012).

O último ponto discutido com as professoras foi sobre o que a música contribui para a cognição da criança. Foi verificado, a partir do questionamento, que as crianças, em sua maioria, ficam mais concentradas, interagem bastante e desenvolvem características próprias com mais facilidade, como a fala, dicção e coordenação motora com o uso da música, estimulando assim, cada vez mais a participação nas aulas. Na fala de outra professora, a música apresentada com algum recurso como chocalhos, panos, colheres, pratos, transmitem segurança às crianças. Todas participam de forma contagiante, cada uma com o seu jeitinho, não ficando ninguém de fora. Como pode ser percebido: no âmbito escolar, uma peça fundamental que não pode falhar é o professor que, muitas vezes, aplica atividade que envolva música sem fundamento e sem objetivos a alcançar (Gatti, 2012).

Para Brito (2003), trazer a música para a escola exige uma formação musical e também a atenção e disposição para ouvir e observar como as crianças percebem e se expressam musicalmente em cada fase de seu desenvolvimento, sempre com o apoio de pesquisas e estudos teóricos que fundamentem o trabalho. Nesse sentido, as ações do professor nas atividades com música são muito valiosas, pois é ele quem ensina, observa, avalia, orienta, é ele quem dá vida às suas aulas e desperta na criança o interesse pela aprendizagem (Gatti, 2012).

Embora não possuam formação na área musical, foi observado que os professores 
selecionados para esta pesquisa buscam conhecimento para desenvolverem atividades musicais com significado, qualidade e conhecimento nesta área. Sendo assim, a música na educação infantil é um instrumento importante na condução das atividades em sala de aula e no desenvolvimento da aprendizagem, bem como no desenvolvimento motor e afetivo da criança.

\section{Considerações Finais}

Esse estudo trouxe resultados que mostram como a linguagem musical é importante na educação infantil, observando os aspectos positivos que ela proporciona ao desenvolvimento da criança, seja cognitivo, emocional ou comportamental.

Como se observou, as professoras que muitas vezes desenvolvem a linguagem musical nem sempre tem formação na área, o que dificulta trabalhar com sua linguagem específica. Entretanto foi observado, entre as professoras, a disposição e o interesse em se trabalhar com as possibilidades que a música traz para enriquecer o ensino na escola. Ela pode ser trabalhada abordando inúmeras vertentes, pensando sempre na comunicação entre a música e os conteúdos disciplinares a serem desenvolvidos.

Sendo assim, a presença da música na educação infantil deixa o ambiente mais alegre e divertido, além de transformar os momentos na escola em uma rica troca de experiências onde a música atua principalmente no desenvolvimento da interação, da criatividade, da memorização, da expressão entre outros aspectos. Como bem coloca Brito (2003, p. 46), “um trabalho pedagógico-musical deve-se realizar em contextos educativos que entendam a música como processo contínuo de construção, que envolve perceber, sentir, experimentar, imitar, criar e refletir”. Portanto, a educação musical não tenciona formar músicos profissionais, mas sim à formação integral das crianças de hoje (Brito, 2003), e é exatamente essa ideia que coadunamos e buscamos meios de difundi-la no ambiente escolar.

\section{Referências}

Alves, R. (2018). A educação dos sentidos. São Paulo: Planeta do Brasil.

Bardin, L. (2016). Análise de conteúdo. Tradução Luís Antero Reto, Augusto Pinheiro. São Paulo: Edições. 
Brasil. (2013). Ministério da Educação e Cultura. Relatório do Parecer CNE/CEB $n^{\circ}$ 12/2013. Brasília.

Brito, TA. (2003). Música na educação infantil/Teca Alencar de Brito; - São Paulo: Peirópolis.

Drummond, E. (2011). Descobrindo sons. - Fortaleza: LMiranda Editora.

Fonseca, V. (2018). Desenvolvimento cognitivo e processo de ensino aprendizagem: Abordagem psicopedagógica à luz de Vygotsky. Petrópolis, RJ: Vozes.

Gardner, H. (1995). Inteligências Múltiplas: A teoria na prática. trad. Maria Adriana Veríssimo Veronese. Porto Alegre: Artmed.

Gatti, R. (2012). A importância da música no desenvolvimento da criança. Disponível em: https://www.academia.edu/37267119/CAMPANHA_NACIONAL_DE_ESCOLAS_DA_COMUNID ADE_FACULDADE_CNECISTA_DE_CAPIVARI_-

FACECAP_PEDAGOGIA_A_IMPORT\%C3\%82NCIA_DA_M\%C3\%9ASICA_NO_DESENVOLVI MENTO_DA_CRIAN\%C3\%87A_RUANA_GATTI_Capivari_SP_2012

Gil, AC. (2008). Métodos e técnicas de pesquisa social. 6.ed. - São Paulo: Atlas.

Granja, CESC. (2010). Musicalizando a escola: música, conhecimento e educação. 2.ed. São Paulo: Escrituras Editora.

Kebach, P. (2016). Processos de interação social em ambiente de educação musical. In: BEYER, E; KEBACH, P. (orgs). Pedagogia da música: experiências de apreciação musical. 3.ed. Porto Alegre: Mediação.

Loureiro, AMA. (2001). O ensino da música na escola fundamental: um estudo exploratório. 2001. 241 f. Dissertação (Mestrado em Educação) - PUC. Belo Horizonte.

Medeiros, JB. (2019). Redação científica: prática de fichamentos, resumo, resenhas. - 13.ed. - São Paulo: Atlas. 
Pereira, AS, Shitsuka, DM, Parreira, FJ \& Shitsuka, R. (2018). Metodologia da pesquisa científica. [e-book]. Santa Maria. Ed. UAB/NTE/UFSM. Disponível em: https://repositorio.ufsm.br/bitstream/handle/1/15824/Lic_Computacao_MetodologiaPesquisa-Cientifica.pdf?sequence $=1$.

Platão. (2017). A República. Tradução Ciro Mioranza. São Paulo: Lafonte.

Rosa, NSS. (1990). Educação musical para a pré-escola. São Paulo: Ática.

Rego, TC. (2014). Vygotsky: Uma perspectiva histórico-cultural da educação. $25^{\mathrm{a}}$ ed. Petrópolis, RJ: Vozes.

Santos, GLS. (2019). A música como instrumento facilitador no processo de ensinoaprendizagem. In: VI Congresso Nacional de Educação, 2019, Fortaleza. Anais Conedu, Editora Realize, 2019. p. 1-5.

Severino, AJ. (2007). Metodologia do trabalho científico. 23.ed. São Paulo: Cortez.

\section{Porcentagem de contribuição de cada autor no manuscrito}

Geysa Luiza de Souza Santos - 50\%

Edione Teixeira de Carvalho - $25 \%$

Odete Selva $-25 \%$ 